ISSN 2638-4981

Volume 1, Issue 2, 2018, PP:24-27

\title{
Subclinical Hyperthyroidism: Should We Treat or Merely Observe?
}

\author{
Deepak Jain*1, Gourab Bhaduri ${ }^{2}$ \\ ${ }^{1}$ Associate professor, Department of Medicine, Pt. B.D. Sharma University of Health Sciences, Haryana, India. \\ ${ }^{2}$ Resident, Department of Medicine, Pt. B.D. Sharma University of Health Sciences, Haryana, India. \\ jaindeepakdr@gmail.com \\ *Corresponding Author: Dr. Deepak Jain, Associate professor, Department of Medicine, Pt. B.D. Sharma University \\ of Health Sciences, Haryana, India.
}

\begin{abstract}
Subclinical hyperthyroidism is defined by a persistently low thyroid stimulating hormone with normal thyroxine and triiodothyronine levels. Epidemiological studies report a prevalence of around $3 \%$, with $50 \%$ of these patients taking levothyroxine. Misleading entities like pituitary or hypothalamic disease, sick euthyroid syndrome and pregnancy, must be ruled out before establishing the diagnosis. In the absence of any unanimously agreed concensus, the ideal approach to its management has been a matter of debate among endocrinologists. The treatment is decided according to the etiology, severity and potential risks of the patient. A step wise approach should be followed for treatment, viz, i: confirmation of diagnosis, ii: evaluation of severity, iii: investigation of the cause, iv: assessment of potential complications, $v$ : if necessary, selection of appropriate treatment. In conclusion, subclinical hypothyroidism management requires careful monitoring through regular assessment of thyroid function.
\end{abstract}

Keywords: Subclinical hyperthyroidism, antithyroid drugs, thyroid function.

Thyroid disorders are the second most common endocrine condition after diabetes mellitus with subclinical thyroid dysfunction comprising a major spectrum of thyroid disease. Although less common than subclinical hypothyroidism, subclinical hyperthyroidism has gained considerable attention with a prevalence of around 0.9 to $3 \%{ }^{1}$

Subclinical hyperthyroidism (SHY) is defined as a patient having normal thyroxine (T4) and triiodothyronine (T3) levels with low or undetectable serum thyroid stimulating hormone (TSH) level. ${ }^{2}$ It denotes evolution of disease at incipient stage. Its pathogenesis is based on the exquisite sensitivity of the hypothalamic-pituitary-thyroid axis. ${ }^{3}$ Serum TSH secretion changes logarithmically with arithmetic changes in serum concentrations of serum T4.,5 Henceforth, alterations in serum $\mathrm{T} 4$ that are within normal range, are capable of producing changes in TSH outside the normal range.
SHY etiologically falls into two categories: endogenous and exogenous. ${ }^{6}$ Exogenous form is more common and is caused by the widespread use of thyroid hormone both to treat hypothyroidism as well as to provide suppressive therapy in patients with non-toxic multi nodular goitres and thyroid cancer. ${ }^{7}$ Endogenous etiologies are toxic multi-nodular goitre, solitary toxic nodule and Graves' disease. ${ }^{8}$ There may be even transient forms of SHY like DeQuervain's thyroiditis and occasionally amiodarone induced thyroiditis. ${ }^{9}$ Other drugs like levodopa, glucocorticoids and dopamine are also implicated in the etiology of transient SHY.

In the U.S.National Health and Nutrition Examination Survey (NHANES) $0.7 \%$ of normal people had serum TSH of less than $0.1 \mathrm{mU} / \mathrm{L}$ while $1.8 \%$ had less than $0.4 \mathrm{mU} / \mathrm{ml}^{10}$ Other concurrent studies have also yielded similar results. The prevalence of subclinical hyperthyroidism increases with age, particularly in 
women. Surprisingly, prevalence of SHY is much higher in iodine deficient areas. The probable pathogenesis behind it is thyroidal autonomy and persistent thyroidal stimulation through $\mathrm{TSH}$ resulting in activating mutations in thyroid follicular epithelium.

Different prospective studies have established that SHY causes significant impairment in quality of life. There is a higher prevalence of palpitations, tremor, heat intolerance, sweating, nervousness, anxiety, reduced feeling of well-being, hostility and inability to concentrate. Even some retrospective studies have claimed predisposition to dementia and Alzheimer's disease. $^{11}$

Cardiovascular events can either be short term like sinus tachycardia, atrial premature beats, atrial fibrillation and long term like impaired diastolic function and systolic dysfunction during effort. ${ }^{12}$ Infact, studies have documented a threefold increased risk of atrial fibrillation in elderly patients with TSH $<0.1 \mathrm{mU} /$. The short term effects are mediated through atrial excitability and shortening of refractory period of the conducting tissue. Increased left ventricular mass is the most consistent cardiac abnormality resulting in long term cardiac events like diastolic and systolic dysfunction. ${ }^{13}$

Thyroid hormones also accelerate the rate of bone remodeling by direct stimulation of osteoclast function. This leads to osteoporosis and increased risk of fractures particularly in post menopausal women. ${ }^{14}$ Different prospective studies have claimed four-fold higher occurrence of hip fractures in women with $\mathrm{TSH}<0.1 \mathrm{mU} / \mathrm{L}$. Interestingly, a study by Zaidi and his colleagues proposed the possibility of TSH deficiency being the cause behind osteoporosis. ${ }^{15}$ This hypothesis is based on the presence of TSH receptors in bones.

Subclinical hyperthyroidism is also responsible for abnormalities in elasticity of arteries, carotid intimamedia thickness, endothelial function and haemostatic profile. Shargodsky et al and Volkze et al have concluded in their studies that elasticity in small and large arteries and CIMT are on a higher side in patients of subclinical hyperythyroidism than euthyroid population. ${ }^{16,17}$ Endothelial dysfunction is believed to be due to increased elevated levels of von Willebrand factor ${ }^{18}$ while adverse effects on haemostatic profile are mediated by raised factor $\mathrm{X}$ and fibrinogen.

In reference to the above discussion subclinical hyperthyroidism appears as a treatable entity.
Nevertheless, there have been controversies and no definite criterion exists for initiation of treatment. It requires individualized approach by judging the clinical consequences in a given patient and thereafter initiate treatment. The initial recommendation is just regular monitoring of the patients' cardiovascular status, coagulation profile and bone mineral density, as isolated low serum TSH levels return spontaneously to normal levels.The risk of progression to overt disease is low with a serum TSH of 0.1-0.4mU/l, while $1-2 \%$ per year of those with serum TSH lower than $0.1 \mathrm{mU} / \mathrm{l}$ develop overt hyperthyroidism. ${ }^{19}$ Only $5 \%$ of patients with autonomous thyroidadenoma and multinodular goitreprogress to overt hyperthyroidism yearly. ${ }^{20}$ Thus as per 2017 American guidelines treatment should be decided by by the etiology as well as stage of the disease and the potential risks in the long run.For instance, exogenous SHY only requires dose adjustment and periodic monitoring of TSH, except in patients with medical history of thyroid neoplasm where chronic TSH suppressive therapy is required. Likewise SHY in Grave's disease often shows spontaneous remission or is almost amenable to treatment with antithyroid drugs. Thus periodic monitoring is a reasonable approach in this scenario. However, co-existence of associated comorbidities like age $>65$ years, osteoporosis or osteopenia, cardiac signs and symptoms like arrhythmia and syncope, or severe SHY with TSH $<0.1 \mathrm{mU} / \mathrm{L}$ warrants aggressive management with radio-iodine ablation. SHY due to underlying nodular goitre or solitary toxic adenoma usually requires ablative treatment withradioiodine or surgery. On the other hand, the thyrotoxic phase of thyroiditis is transitory with a spontaneous remission in 2 to 3 months, requiring no treatment or symptomatic treatment at the most with beta blockers. The following algorithm illustrates the approach: ${ }^{21}$

Treatment for SHY also predisposes the patients to certain risks. Radio iodine ablation is likely to render the patient hypothyroid and also precipitate thyroid ophthalmopathy. Such patients require life long levothyroxine supplementation at doses high enough to suppress TSH levels. ${ }^{22}$ This puts them at risk of developing atrial fibrillation at a rate of 1 for every 14 patients as postulated in Frammingham Cohort Study. ${ }^{23}$ Thus, these potential adversities should be weighed against the expected benefits before initiating treatment. 


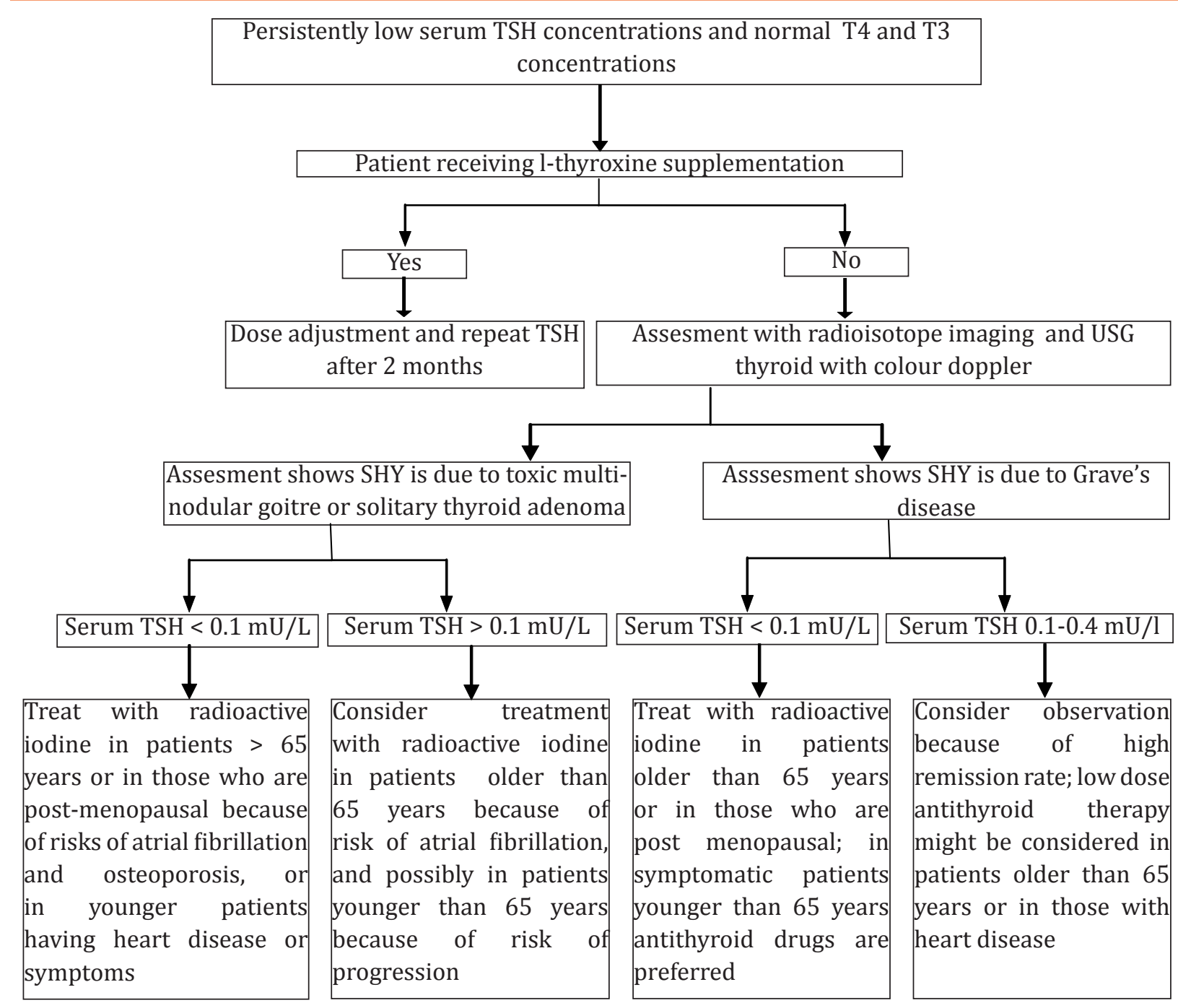

To summarise, SHY has significantimpact on the quality of life but dearth of prospective randomized control studies has limited making an organized treatment protocol Instead, there are smaller studies reporting benefits of treatment on secondary end points like heart rate, cardiac output, atrial and ventricular premature beats. The options for treatment at our disposal remain the same as for overt hyperthyroidism like antithyroid drugs, beta blockers, radio iodine ablation and surgery. It only requires clinical acumen for justified use of these modalities for improvement in patient's quality of life.

\section{REFERENCES}

[1] Vanderpump MPJ. The epidemiology of thyroid diseases. InWerner and Ingbar's the Thyroid: a Fundamental Clinical Text.Philadelphia: JbLippincott-Raven; 2005: edn 9, EdsBraverman LE, Utiger RD: pp 398-406.

[2] ImadKaffilmout,Lynne 2006; 55(6): 543-4.

[3] Carr D, McLeod DT, Parry G, Thornes HM. Fine adjustment of thyroxine replacement dosage: comparison of the thyrotropin releasing hormone test using sensitive thyrotropin assay with measurement of free thyroid hormone and clinical assessment. Clinical Endocrinology.1998; 28: 325-33.

[4] Spencer CA, Lopresti JS, Patel A, Guller RB, Eigen A, Shen D, et al. Applications of a new chemiluminescent thyrotropin assay to subnormal measurement. Journal of Clinical Endocrinology and Metabolism.1990; 70: 453-60.

[5] Meier CA, Maisen MN, Lowry A, Muller J, Smith A. Interindividual differences in the pituitary thyroid axis influence the interpretation of thyroid function tests. Clinical Endocrinology.1993;39: 101-7. 
Subclinical Hyperthyroidism: Should We Treat or Merely Observe?

[6] Ross DS. Subclinical thyrotoxicosis. In Werner and Ingbar's The Thyroid: A Fundamental and Clinical Text. Philadelphia: Lippincott Williams and Wilkins.2000; edn 8. EdsBraverman LE, Utiger RD: pp 1016-20.

[7] Cannaris GJ, Manovitz NR, Mayor G, Ridgway EC. The Colorado thyroid disease prevalence study. Archives of Internal Medicine.2000; 160: 526-34.

[8] Scott DJ, McLellan AR, Finlayson J, Chu P, Alexander WD. Elderly patients with suppressed serum TSH but normal free thyroid levels usually have mild thyroid overactivity and are at risk of developing overt hypothyroidism. Quarterly Journal of Medicine.1991; 78: 77-84.

[9] Spencer C, Eigen A, Shen D, Duda M, Qualis S, Weiss S,Nicoloff J. Specificity of sensitive assay of thyrotropin(TSH) used to screen thyroid disease in hospitalized patients. Clinical Chemistry.1987; 33:1391-6.

[10] Santos Palacios S, Pascual-Corrales E, Galofre JC. Management of Subclinical Hyperthyroidism. International Journal of Endocrinology and Metabolism. 2012; 10(2): 490-6.

[11] Kalmijn S, Mehta KM, Pols HA, Hofman A, Drexhage HA, Breteler MM. Subclinical hyperthyroidism and risk of dementia. The Rotterdam Study. Clinical Endocrinology.2000; 53: 733-7.

[12] Maor E, Kivity S, Kopel E, Segev S, Sidi Y, Goldenberg I, et al. Differences in heart rate profile during exercise among subjects with subclinical thyroid disease. Thyroid.2013; 23: 1226-32.

[13] Asvold BO, Bjoro T, Platou C, Vlatten LJ. Thyroid function and the risk of coronary heart disease: 12 year followup of the HUNT study in Norway. Clinical Endocrinology.2012; 77: 911-7.

[14] Grimnes G, Emaus N, Joakimsen RM, Figenschau $\mathrm{Y}$, Jorde $\mathrm{R}$. The relationship between serum TSH and bone mineral density in men and postmenopausal women: the Tromso study. Thyroid.2008; 18: 1147-55.

[15] 15.Zaidi M, Davies TF, Zallone A. Thyroid stimulating hormones,thyroid hormones and bone loss. Current Osteoporosis Reports. 2009; 7: 4752 .

[16] Shargodsky M, Serov S, Gavish D. Long term thyrotropin suppressive therapy with levothyroxine impairs small and large artery elasticity and increases left ventricular mass in patients with thyroid dysfunction. Thyroid.2006; 16: 381-6.

[17] Volkze H, Robinson DM, Schminke U. Thyroid function and carotid wall thickness. Journal of Clinical Endocrinology and Metabolism.2004; 89: 2145-9.

[18] Palmeiro C, Davila MI, Bhat M, Frishman William H, Weiss IA. Subclinical Hyperthyroidism and Cardiovascular Risk: Recommendations for Treatment. Cardiology in Review.2013; 21: 300-8.

[19] Parle JV, Franklyn JA, Cross KW, Jones SC, Sheppard MC. Prevalence and followup of abnormal thyrotrophin concentrations in the elderly in the United Kingdom.Clinical Endocrinology.1991; 34: 77-83.

[20] Stanbury JB, Ermans AE, Bourdoux P, Todd $\mathrm{C}$, Oken E, Tonglet $\mathrm{R}$, etal. Iodine induced hyperthyroidism: Occurrence and epidemiology. Thyroid.1998; 8: 83-100.

[21] Cooper DS, Biondi B. Subclinical Thyroid Disease. Lancet.2012; 379: 1142-54.

[22] Pearche SHS. Spontaneous reporting of adverse reaction to carbimazole and propylthiouracil in the United Kingdom.Clinical Endocrinology.2004; 61: 589-94.

[23] Vanderpump MPJ. Should we treat mild hyprthyroidism.European Journal of Internal Medicine.2011; 22: 330-3.

Citation: Deepak Jain, GourabBhaduri. Subclinical Hyperthyroidism: Should We Treat or Merely Observe?. Archives of Diabetes and Endocrine System. 2018; 1(2): 24-27.

Copyright: (C) 2018 S. Deepak Jain, Gourab Bhaduri. This is an open access article distributed under the Creative Commons Attribution License, which permits unrestricted use, distribution, and reproduction in any medium, provided the original work is properly cited. 